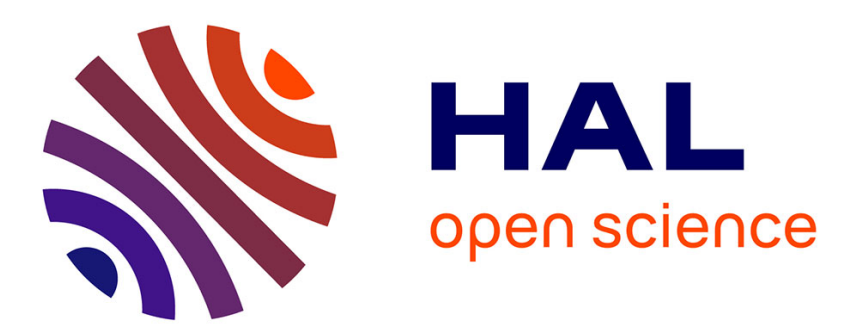

\title{
Effect of alloying on mechanical properties of as cast ferritic nodular cast irons
}

Jon Sertucha, Jacques Lacaze, Joan Serrallach, Ramon Suarez, F. Osuna

\section{To cite this version:}

Jon Sertucha, Jacques Lacaze, Joan Serrallach, Ramon Suarez, F. Osuna. Effect of alloying on mechanical properties of as cast ferritic nodular cast irons. Materials Science and Technology, 2012, vol. 28, pp. 184-191. 10.1179/1743284711Y.0000000014 . hal-00859928

\section{HAL Id: hal-00859928 https://hal.science/hal-00859928}

Submitted on 9 Sep 2013

HAL is a multi-disciplinary open access archive for the deposit and dissemination of scientific research documents, whether they are published or not. The documents may come from teaching and research institutions in France or abroad, or from public or private research centers.
L'archive ouverte pluridisciplinaire HAL, est destinée au dépôt et à la diffusion de documents scientifiques de niveau recherche, publiés ou non, émanant des établissements d'enseignement et de recherche français ou étrangers, des laboratoires publics ou privés. 


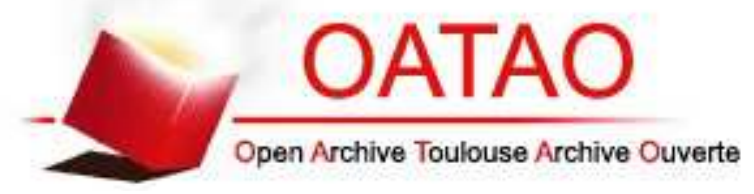

\section{Open Archive TOULOUSE Archive Ouverte (OATAO)}

OATAO is an open access repository that collects the work of Toulouse researchers and makes it freely available over the web where possible.

This is an author-deposited version published in : http://oatao.univ-toulouse.fr/ Eprints ID : 8770

To link to this article : DOI:10.1179/1743284711Y.0000000014 URL : http://dx.doi.org/10.1179/1743284711Y.0000000014

To cite this version : Sertucha, Jon and Lacaze, Jacques and Serrallach, Joan and Suarez, Ramon and Osuna, F. Effect of alloying on mechanical properties of as cast ferritic nodular cast irons. (2012). Materials Science and Technology, vol. 28 ( $\left.\mathrm{n}^{\circ} 2\right)$. pp. 184-191. ISSN 0267-0836

Any correspondance concerning this service should be sent to the repository administrator: staff-oatao@ listes-diff.inp-toulouse.fr 


\title{
Effect of alloying on mechanical properties of as cast ferritic nodular cast irons
}

\author{
J. Sertucha ${ }^{1}$, J. Lacaze ${ }^{* 2}$, J. Serrallach ${ }^{3}$, R. Suárez ${ }^{1}$ and F. Osuna ${ }^{3}$
}

\begin{abstract}
The development of low temperature applications for ferritic nodular cast irons calls for improved materials in the as cast state, e.g. for off-shore windmills components. Within this line of work, a series of 68 castings were prepared with the same casting procedure and slight changes in composition. The tensile properties at room temperature, as well as the impact energy for rupture at room temperature, $-20^{\circ} \mathrm{C}$ and $-40^{\circ} \mathrm{C}$, were measured. Outputs from multivariate analysis performed on the data are then discussed and compared to literature results, putting emphasis on the properties of the ferritic matrix.
\end{abstract}

Keywords: Nodular cast iron, Ferritic matrix, Mechanical properties, Low temperature, Impact properties

\section{Introduction}

Room temperature (RT) mechanical properties of nodular cast irons have been characterised for many years, and the effect of ferrite over pearlite fraction is well established. However, most of the previous studies attempted to relate these mechanical properties to the nominal composition of the alloys at given casting conditions without quantitative consideration to the relative amount of pearlite and ferrite. This is the case of the extensive statistical studies reported by Watmough et $a .^{1}{ }^{1}$ and Goodrich and Lobenhofer. ${ }^{2}$ Optimum levels of the addition of several alloying elements that mainly reflect the influence of the ferrite/pearlite ratio rather than an intrinsic effect on ferrite are thus reported.

Some attempts have, however, been made to consider the matrix of cast irons as a composite made of ferrite and pearlite. A composite matrix microhardness $(\mathrm{CMMH})$ has been defined ${ }^{3,4}$ as $\mathrm{CMMH}=H B_{\alpha} f^{\alpha}+H B_{\mathrm{p}} f^{\mathrm{p}}$, which relates the hardnesses of ferrite $H B_{\alpha}$ and pearlite $H B_{\mathrm{p}}$ to fractions of ferrite $f^{\alpha}$ and pearlite $f^{\mathrm{p}}$. Having been able to correlate the ferrite/pearlite ratio observed in their experiments with the composition of the studied alloys, Venugopalan and Alagarsamy ${ }^{3}$ observed that the CMMH parameter correlates linearly satisfactorily with ultimate tensile strength UTS, yield strength $Y$ and elongation at rupture $A$ for the investigated series of alloys in either as cast, annealed or normalised states. ${ }^{3}$ Although Venugopalan and Alagarsamy ${ }^{3}$ did not specify it, it is guessed that their relations between ferrite and pearlite hardnesses and composition data were respectively obtained on annealed samples that were fully ferritic and normalised samples that were fully pearlitic. The coefficients

${ }^{1}$ Engineering and Foundry Processes Department, AZTERLAN, Aliendalde Auzunea 6, Durango, E-48200 Bizkaia, Spain

${ }^{2}$ CIRIMAT, Université de Toulouse, ENSIACET, BP 44362, 31030 Toulouse Cedex 4, France

${ }^{3}$ INFUN, S.A., Camí Can Ubach 25, 08620 Sant Vicenç dels Horts, Barcelona, Spain

*Corresponding author, email jacques.lacaze@ensiacet.fr they obtained for the effect of $\mathrm{Si}, \mathrm{P}, \mathrm{Mn}, \mathrm{Cu}, \mathrm{Ni}$ and $\mathrm{Mo}$ on ferrite hardness are listed in Table 1.

Some other values on the effect of alloying additions were found, which are also reported in Table 1 for comparison. On annealed samples, Levin et al. $^{7}$ showed that $\mathrm{Sn}$ up to $0 \cdot 15 \mathrm{wt}-\%$ has no significant effect on either of the $\mathrm{RT}$ mechanical properties, while $\mathrm{Cu}$ varying from residual to $1 \mathrm{wt}-\%$ has a significant effect (see Table 1). Kippola and Goodrich ${ }^{9}$ reported the statistical analysis of the mechanical properties of annealed cast irons with various amounts of several elements, although the changes in composition were in fact quite limited apart for $\mathrm{C}$ and $\mathrm{Si}$. The most significant correlations they obtained were for $Y$ and UTS, which were found to be sensitive to $\mathrm{C}, \mathrm{Si}$ and $\mathrm{Ni}$. The coefficients for these two latter elements are also listed in Table 1. From the tabulated results in the work of Nobuki et al., ${ }^{10}$ some data on the effect of Ni could be also estimated. All other values listed in Table 1 are for as cast materials. ${ }^{5,6}$ The coefficient for the effect on $A$ in the study of Björkegren et al. ${ }^{5}$ was estimated from the graph provided, while all the others were listed in the original work. The coefficients associated to the study of Frenz ${ }^{6}$ were taken from the work of Donelan. ${ }^{11}$ They may not be the original ones, as this latter author added the effect of grain size on $Y$ and UTS from another source without giving much detail. The values associated to $\mathrm{Ni}$ from the ASM handbook ${ }^{8}$ were in fact estimated from the graphs provided in this handbook. When several values are available for a given species, Table 1 shows the works that reported results of the same magnitude for each alloying element investigated, with the exception of $\mathrm{Ni}$ for which the changes are larger.

Low temperature impact properties of cast irons have also been studied for many years, and the strong effect of silicon, which increases dramatically the ductile to brittle temperature (TDB), is well established. ${ }^{12}$ This is illustrated in Fig. 1, where the impact energy values are about 2-2.5 times higher than generally reported because of the use of dedicated specimens, though the transition temperature was unchanged with respect to 


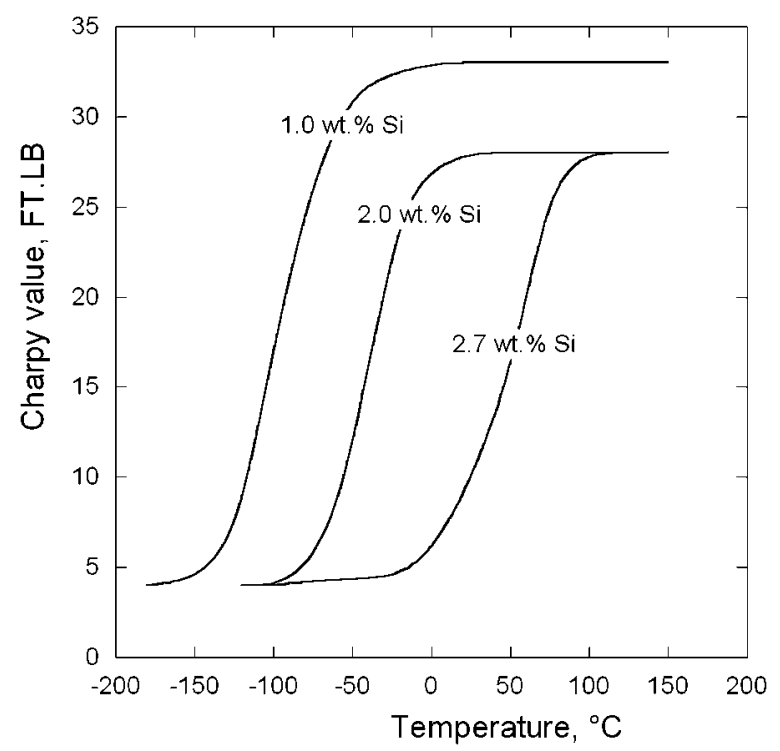

1 Effect of temperature on impact energy of notched samples of various silicon contents, after Gilbert: ${ }^{12}$ impact energy values are higher than usually reported because of use of dedicated samples, but transition temperatures are unchanged with respect to standard impact samples (see text)

standard specimens. ${ }^{12}$ Phosphorus is also known to affect negatively cast irons, both decreasing the impact energy and increasing the transition temperature. ${ }^{8}$ Angus ${ }^{13}$ mentions that nickel and manganese increase as well the transition temperature. For nickel, this appears in contrast with its effect on pure iron, ${ }^{14}$ but seems confirmed by the schematic representing the effect of alloying elements in the ASM handbook. ${ }^{8}$ However, neither in Angus' monograph nor in the ASM handbook did appear any details about the microstructure of the tested alloys, namely the pearlite content of the matrix. The only information on the effect of $\mathrm{Ni}$ found up to now for fully ferritic matrix is due to Nobuki et al., ${ }^{10}$

Table 1 Effect of some alloying elements on mechanical properties of nodular ferritic cast irons: values listed correspond to $1 \mathrm{wt}-\%$ addition of any of elements listed

\begin{tabular}{|c|c|c|c|c|c|c|c|}
\hline & $\mathrm{Si}$ & $P$ & $\mathrm{Mn}$ & $\mathrm{Cu}$ & $\mathrm{Ni}$ & Mo & References \\
\hline \multirow[t]{6}{*}{$\bar{Y}$} & $109 \cdot 6$ & 449 & & & & & 5 \\
\hline & $63 \cdot 2$ & & & & & & 6 \\
\hline & & & & 28 & & & 7 \\
\hline & & & & & 44 & & 8 \\
\hline & 77.9 & & & & 8.9 & & 9 \\
\hline & & & & & 43 & & 10 \\
\hline \multirow[t]{6}{*}{ UTS } & 79.5 & 575 & & & & & 5 \\
\hline & $68 \cdot 1$ & & & & & & 6 \\
\hline & & & & 14 & & & 7 \\
\hline & & & & & 22 & & 8 \\
\hline & $71 \cdot 6$ & & & & $5 \cdot 4$ & & 9 \\
\hline & & & & & 36 & & 10 \\
\hline \multirow[t]{3}{*}{$A$} & & & & -4 & & & 7 \\
\hline & $-2 \cdot 76$ & & & & & & 5 \\
\hline & & & & & $-1 \cdot 4$ & & 10 \\
\hline \multirow[t]{6}{*}{$H B_{\alpha}$} & 44 & 114 & 9 & 10 & 7 & 22 & 3 \\
\hline & 37 & & & & & & 4 \\
\hline & $26 \cdot 1$ & 194 & & & & & 5 \\
\hline & & & & 12 & & & 7 \\
\hline & & & & & 9 & & 8 \\
\hline & & & & & 15 & & 10 \\
\hline
\end{tabular}

who reported (their Fig. 8, $0 \cdot 1 \% \mathrm{Mn}$ series, annealed) that $3 \mathrm{wt}-\% \mathrm{Ni}$ slightly decreases the impact energy at RT of notched samples while it does not change the impact energy at RT of unnotched samples.

The impact properties were also studied by Jolley and Gilbert, ${ }^{15}$ putting emphasis on the effect of segregation in relation with casting thickness. This relation is due to the presence of coarse eutectic carbides, which strongly increase the TDB temperature and are more numerous in large than in thin sections. On the annealed material, the sensitivity to casting thickness was observed to decrease and even to disappear in case of long enough annealing to dissolve the remaining traces of carbides. A final note about the impact properties concerns the effect of nodule counts. Labrecque et al. ${ }^{16}$ mentioned the significant effect of nodule count as established at QIT Fer et Titane. Higher counts were observed to decrease the upper shelf energy but decrease at the same time the TDB temperature. This effect has been recently confirmed by Caldera et al. ${ }^{17}$

The present work was intended to study the effect of carbon and silicon content, as well as that of low level addition of several elements, on the mechanical properties of as cast ferritic nodular cast irons at RT and impact energy at $\mathrm{RT},-20^{\circ} \mathrm{C}$ and $-40^{\circ} \mathrm{C}$. Emphasis was put on the properties of ferrite, while those of pearlite have been previously investigated. ${ }^{18}$ During the present investigation, the amount of silicon has been varied from $4 \cdot 16 \mathrm{wt}-\%$ to an unusual low value of $1.51 \mathrm{wt}-\%$.

\section{Experimental}

A total of 68 alloys were prepared in a medium frequency induction furnace $(250 \mathrm{~Hz}, 100 \mathrm{~kW}) 100 \mathrm{~kg}$ in capacity. The charge was composed of $30-50 \%$ automotive steel scrap and 70-50\% low alloyed pig iron. Its composition was adjusted according to the required $\mathrm{Mn}$ and $\mathrm{P}$ contents, which are the main contributions from the steel scrap and the low alloyed pig iron used respectively. After melting, the contents in carbon, silicon and other selected alloying elements were checked and adjusted to the specified values. The melt temperature was then increased to $1500-1510^{\circ} \mathrm{C}$, and its surface was skimmed before being poured in a $50 \mathrm{~kg}$ capacity ladle for treatment with a nodulariser $(42-44 \mathrm{wt}-\% \mathrm{Si}$, $5-6 \mathrm{wt}-\% \mathrm{Mg}, 0 \cdot 9-1 \cdot 0 \mathrm{wt}-\% \mathrm{Ca}, 0 \cdot 4-0.5 \mathrm{wt}-\% \mathrm{Al}$ and $0 \cdot 9$ $1 \cdot 1 \mathrm{wt}-\% \mathrm{RE}$ ) by the sandwich method. The treatment temperature was between 1470 and $1490^{\circ} \mathrm{C}$. After completion of the reaction, the $\mathrm{Mg}$ treated batches were transferred to the pouring area, where the alloys were cast in chemically bonded sand moulds that contained standard keel blocks (Fig. 2). Inoculation treatment was carried out by adding $\sim 0.15 \mathrm{wt}-\%$ of commercial inoculant $(68.1$ wt- $\% \mathrm{Si}, 0.89$ wt- $\% \mathrm{Al}, 1.65$ wt- $\% \mathrm{Ca}, 0.45 \mathrm{wt}-\% \mathrm{Bi}$, $0.38 \mathrm{wt}-\% \mathrm{Ba}$ and $0.37 \mathrm{wt}-\% \mathrm{RE}$ ) into the cavity of the moulds. Table 2 lists the composition range of all the elements measured on the cast parts.

Although no specific additions of $\mathrm{Zr}$ and $\mathrm{Nb}$ were made, it is seen that these elements were sometimes detected at a very low level. In addition, while both the nodularising treatment and the inoculation were always made in the same conditions, it is seen that $\mathrm{Al}$ and $\mathrm{Bi}$ were sometimes not detected in the cast material, while the amount of $\mathrm{Mg}$ is observed to vary significantly. Elements such $\mathrm{P}, \mathrm{S}$ and $\mathrm{N}$ do as well vary significantly depending on the charge material. 


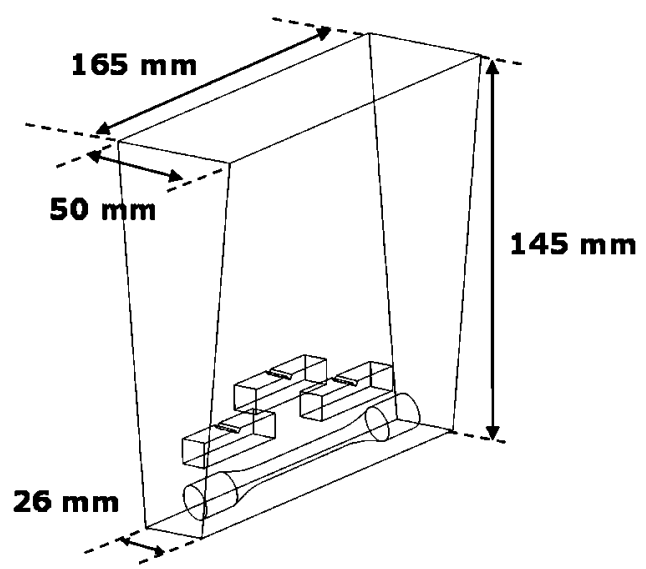

2 Keel block used for all castings showing locations where mechanical test samples were machined from

After solidification and cooling, one standard tensile specimen $(10 \mathrm{~mm}$ in diameter) was machined from the lower part of each keel block (see Fig. 2) on which the rupture stress UTS, the rupture strain $A$ and the yield strength $Y$ were measured. In addition, three impact energy specimens (KV type with dimensions of $10 \times 10 \times 55 \mathrm{~mm}$ ) were also machined from the same area to determine the impact strength at $\mathrm{RT},-20^{\circ} \mathrm{C}$ and $-40^{\circ} \mathrm{C}$. After the tensile tests, the specimens were used for the determination of the Brinell hardness $H B$ using a $10 \mathrm{~mm}$ diameter sphere and a load of $3000 \mathrm{~kg}$. Finally, the samples were cut and prepared for subsequent metallographic characterisation. The nodule count $N_{\mathrm{A}}$ and the nodularity were evaluated by quantitative image analysis, while the fractions of ferrite $f^{\alpha}$ and pearlite $f^{\text {per }}$ were determined by comparing the microstructure obtained after etching with $5 \%$ nital against standard reference microstructures. ${ }^{19,20}$ All the iron samples analysed in the present work showed a nodularity index $>90 \%$, while the nodule count varied from 190 to $590 \mathrm{~mm}^{-2}$. The maximum pearlite fraction in the matrix was $35 \%$, while 31 of them had more than $98 \%$ ferrite and will be later designated as fully ferritic. In a few cases, the matrix was found to contain coarse carbides, and six experiments showing more than $2 \%$ of these latter were disregarded for further analysis.

\section{Statistical analysis of properties}

All statistical analyses were performed using JMP software. It was first attempted to find a relation between the composition and the pearlite fraction at given casting conditions as reported by other authors, ${ }^{3}$ here including also the nodule count. As the present study complements a previous similar work on pearlitic grades, ${ }^{18}$ a first trial was carried out with the results from both studies. This attempt was unsuccessful, with residuals by far too high for the correlation obtained to be satisfactory, i.e. useful. A second trial limited to the ferritic grades was then performed, which showed again quite a low correlation $R^{2}$ coefficient at $0 \cdot 75$.

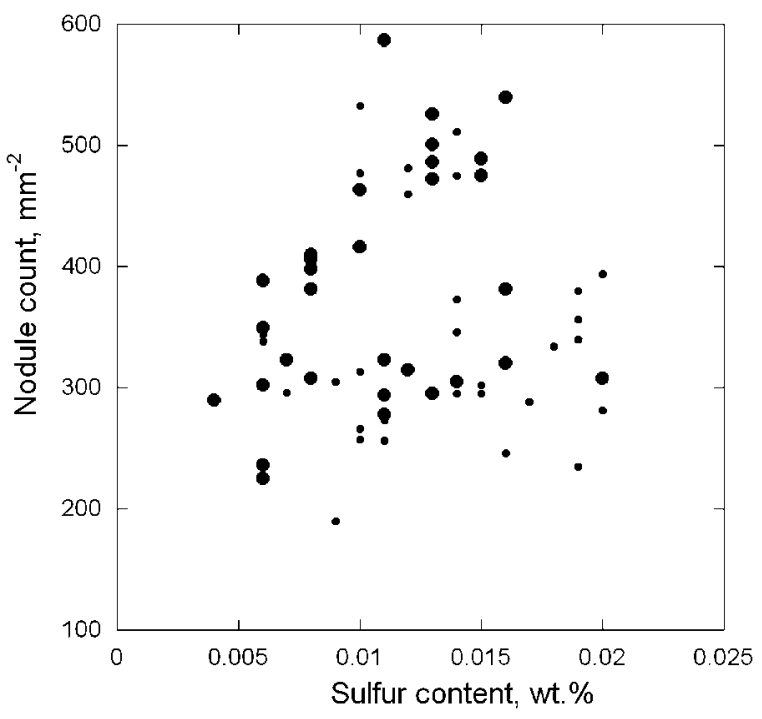

3 Evolution of nodule count with sulphur content: large circles are for fully ferritic materials, small ones are for those containing some pearlite

The known effect of nodule count on pearlite fraction suggested looking for any statistical description of $N_{\mathrm{A}}$ as a function of composition. As for pearlite, the multivariate analysis led to a quite poor correlation with an $R^{2}$ factor of $\sim 0 \cdot 70$. The large scattering of the data could indeed be related to a twofold behaviour of $N_{\mathrm{A}}$ with respect to a few species, in particular to sulphur, as illustrated in Fig. 3. In this figure, it is further observed that this behaviour seems independent from the fact that the material is fully ferritic (large symbols) or contains some pearlite (small symbols). Looking systematically at the data, a decrease in $\mathrm{Mg}$ and an increase in $\mathrm{P}$ with increasing $\mathrm{S}$ content were noticed. Furthermore, both $\mathrm{Ti}$ and $\mathrm{Cu}$ showed a twofold evolution with $\mathrm{S}$ content, with results either insensitive to the $S$ content or increasing with it. These latter values could be associated with materials presenting some pearlite, which may mean that some sulphur was sometimes introduced together with $\mathrm{Ti}$ and $\mathrm{Cu}$. To sum up, it seems that very complex chemical reactions took place during melt preparation and handling, leading to a significant scattering of the pearlite and $N_{\mathrm{A}}$ values that prevent any possibility from expressing them as accurate function of composition.

\section{Tensile properties and hardness}

A multivariate analysis was applied to characterise $Y$, $U T S, A$ and $H B$ with compositions, nodule count $N_{\mathrm{A}}$ $\left(\mathrm{mm}^{-2}\right)$ and pearlite fraction $f^{\text {per }}(\%)$ as input variables. It is noted that each quantity could be given as a polynomial of these variables, with possibly second order terms

$$
\begin{aligned}
\text { Predicted property value }= & a_{0}+a_{\mathrm{N}_{\mathrm{A}}} N_{\mathrm{A}}+b_{\mathrm{N}_{\mathrm{A}}} N_{\mathrm{A}} N_{\mathrm{A}} \\
& +a_{\mathrm{per}} f^{\text {per }}+b_{\mathrm{per}} f^{\text {per }} f^{\text {per }} \\
& +\sum a_{\mathrm{i}} w_{\mathrm{i}}+\sum b_{\mathrm{ij}}\left(w_{\mathrm{i}} w_{\mathrm{j}}\right)^{2}
\end{aligned}
$$

\begin{tabular}{|c|c|c|c|c|c|c|c|c|c|c|c|c|c|c|c|}
\hline & $\mathrm{C}$ & $\mathrm{Si}$ & B & $\mathrm{Cu}$ & $\mathrm{Mn}$ & $\mathrm{Ni}$ & $\mathrm{Ti}$ & $\mathrm{Al}$ & $\mathrm{Bi}$ & $\mathrm{Mg}$ & $\mathrm{N}$ & $\mathrm{P}$ & $\mathrm{S}$ & $\mathrm{Nb}$ & $\mathrm{Zr}$ \\
\hline Minimum & 3.36 & 1.51 & 0 & 0.01 & 0.09 & 0 & 0 & 0 & 0 & 0.021 & 0.0032 & 0.017 & 0.004 & 0 & 0 \\
\hline Maximum & 4.08 & $4 \cdot 16$ & 0.032 & 0.15 & 0.39 & 0.27 & 0.028 & 0.017 & 0.005 & 0.059 & 0.0077 & 0.042 & 0.02 & 0.012 & 0.003 \\
\hline
\end{tabular}

Table 2 Composition range of all elements measured on cast parts, wt-\% 
where the composition variables $w_{\mathrm{i}}$ are the contents in ' $\mathrm{i}$ ' species expressed in weight per cent, and the $a$ and $b$ coefficients are the regression coefficients.

A first analysis was performed on the fully ferritic alloys only for characterising the most important effects. After a first run that indicated variables or cross-terms of some significance, a second analysis was carried out when only the most relevant variables (namely with a probability of not being significant $<5 \%$ ) were selected. The coefficients thus obtained are listed in Table 3 with the label 'ferritic'. The $R^{2}$ correlation coefficients obtained were quite high at $0.98,0.98,0.82$ and 0.97 for $Y$, $U T S, A$ and $H B$ respectively.

A two-step procedure was then similarly applied to the whole set of data, consisting first of identifying the most relevant correlations and then calculating the regression coefficients. However, for the purpose of comparison, all the variables identified for the fully ferritic alloys were kept in this second step even if they did not appear significant. The regression terms obtained on the whole set of alloys are listed in Table 3 with the label 'all alloys'. The $R^{2}$ correlation coefficients were slightly lower than the previous ones but were still quite high at 0.94 for $Y, 0.93$ for $U T S, 0.83$ for $A$ and 0.89 for $H B$.

Both correlations are illustrated in Fig. 4, where the graphs compare the calculated to experimental values of $Y$, UTS, $A$ and $H B$, with crosses for fully 'ferritic' alloys and solid circles for 'all alloys'.

In Table 3 , it is seen that $w_{\mathrm{Si}}$ is the only variable that appears for all properties in both regressions. The influence of this species will be further detailed in the section on 'Discussion'. $\mathrm{Ni}, \mathrm{Cu}, \mathrm{C}, \mathrm{N}$ and $\mathrm{Al}$ appear to have consistent effects in both regressions when they do appear as relevant variable. On the contrary, B, Bi and $N_{\mathrm{A}}$ show contrasted coefficients when they appear in both correlations ('ferritic' and 'all alloys') for any one of the properties. Finally, $\mathrm{Ti}, \mathrm{Zr}, \mathrm{Mn}, \mathrm{P}, \mathrm{Nb}$ and $\mathrm{S}$ appear as significant species only for statistics on 'all alloys'. It is suggested that this is related to the correlation with the nodule count mentioned above.

\section{Impact properties}

The results obtained at the three investigated temperatures are all plotted as a correlation between impact energy and hardness measured at RT in Fig. 5. Although the scatter is high, there is a clear negative correlation that may mostly be related to pearlite fraction, which decreases the impact energy while increasing the hardness.

For the impact energy to be at least $12 \mathrm{~J}$ at $-40^{\circ} \mathrm{C}$ as for EN-GJS-350-22-LT grade, it is seen that three sets of data meet this target in Fig. 5. In fact, they correspond to five alloys that all had low silicon content $(<2 \cdot 1 \mathrm{wt}-\%)$ and high nodule count $\left(>300 \mathrm{~mm}^{-2}\right)$. However, some of the materials investigated also had low silicon content at $2 \cdot 0-2 \cdot 1 \mathrm{wt}-\%$ and quite large nodule counts (235$500 \mathrm{~mm}^{-2}$ ) but did not meet the target, reaching at most $6 \mathrm{~J}$. Looking at the compositions, it was seen that the alloys meeting the target had lower P $(0 \cdot 017-0 \cdot 024 \mathrm{wt}-\%)$ and $\mathrm{S}(0 \cdot 004-0.008 \mathrm{wt}-\%)$ than the other alloys $(0 \cdot 029$ $0 \cdot 040 \mathrm{wt}-\% \mathrm{P}$ and $0 \cdot 013-0 \cdot 019 \mathrm{wt}-\% \mathrm{~S}$ ).

Multivariate statistical analysis was performed on the three series of data, i.e. related to $\mathrm{RT},-20^{\circ} \mathrm{C}$ and $-40^{\circ} \mathrm{C}$. The strategy for selecting the variables was slightly different here, as it was aimed at looking for the temperature effect. Thus, a first screening of the

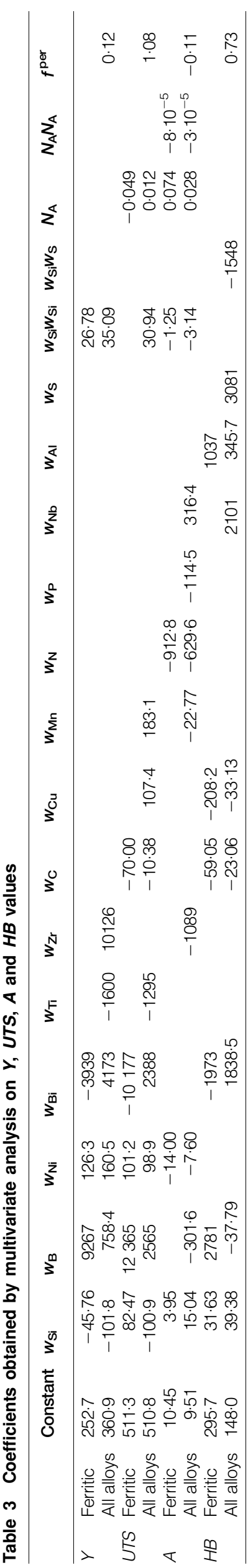



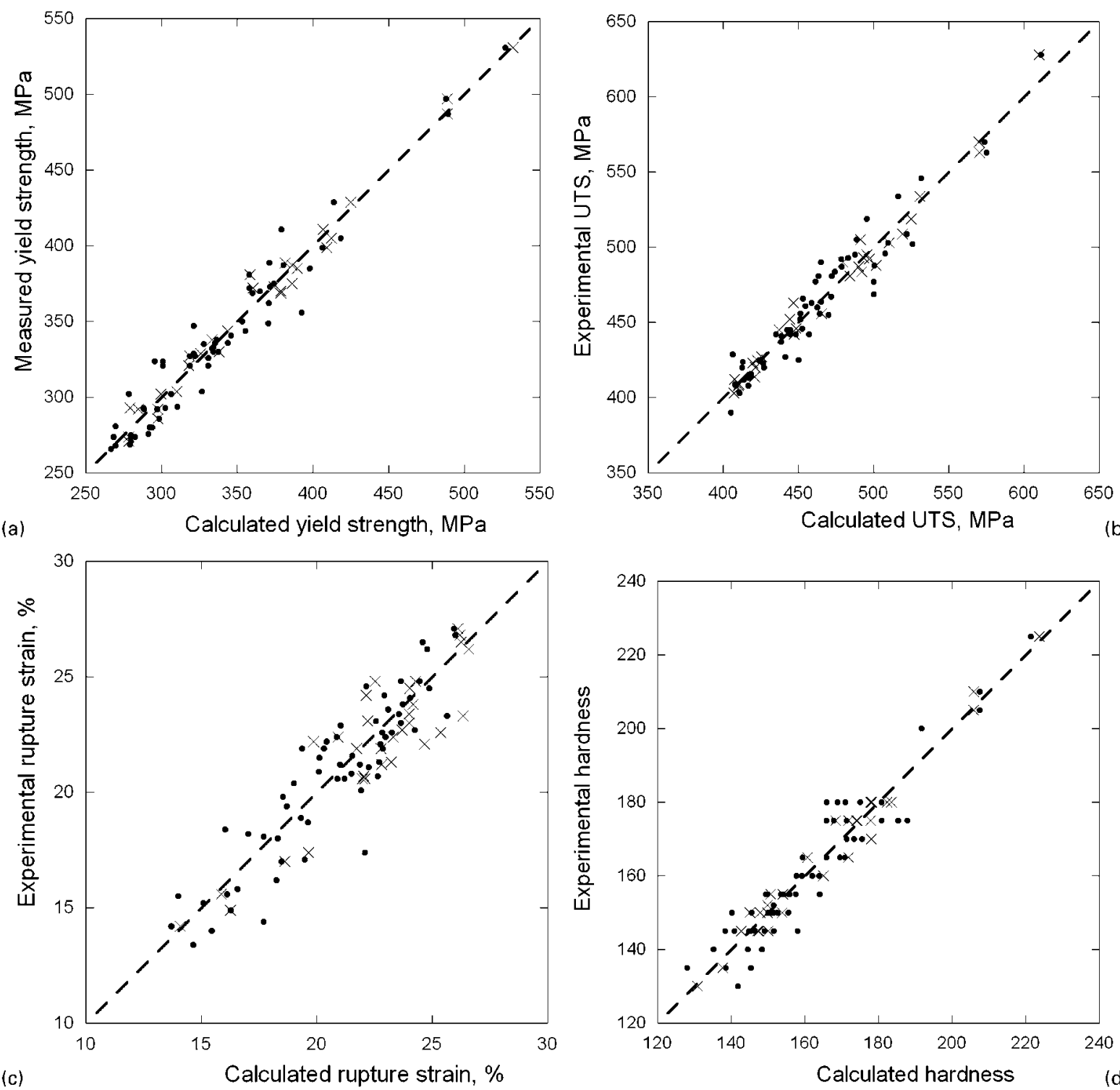

4 Comparison of calculated and measured values of a $Y, b$ UTS, $c A$ and $d H B$ : interrupted line in each graph is bisector; solid circles correspond to correlations obtained from statistical analysis on all samples, and crosses relate to fully ferritic materials

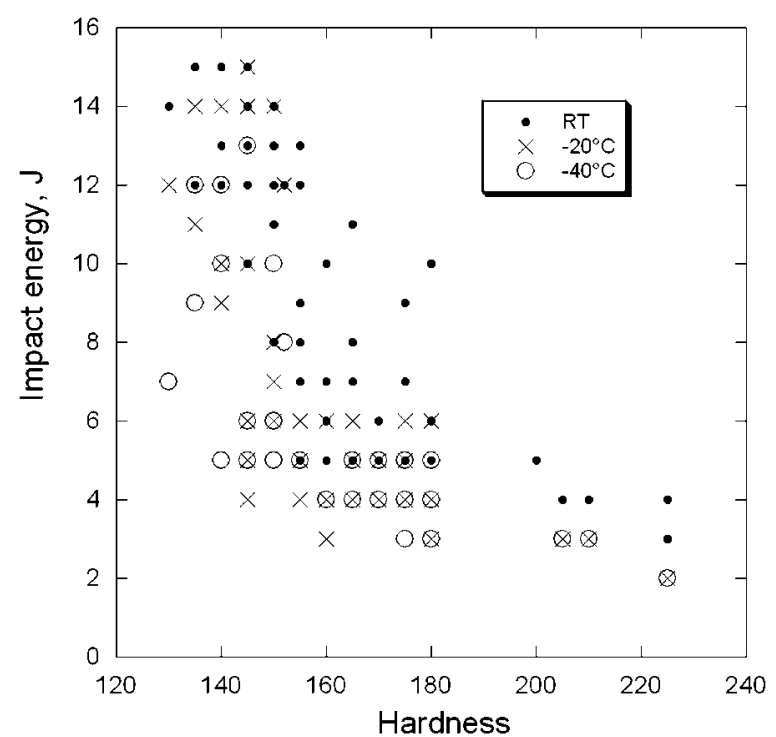

5 Correlation between impact energy for various temperatures $\left(\mathrm{RT},-20^{\circ} \mathrm{C}\right.$ and $-40^{\circ} \mathrm{C}$ ) and hardness measured at $\mathbf{R T}$ correlations was made for all three series of data for fully ferritic alloys, and every variable that appeared significant at any temperature was selected. The statistical analysis was then performed with the whole set of selected variables, namely $\mathrm{Si}, \mathrm{B}, \mathrm{N}$ and $\mathrm{S}$ contents, plus $N_{\mathrm{A}}$. The results are listed in Table 4 , where the regression coefficient $R^{2}$ obtained is also given, and Fig. $6 a$ presents calculated versus measured impact values. Then, a similar screening was carried out on the whole set of data, and a few additional composition variables were found to be significant for at least one of the temperatures. Thus, $\mathrm{Cu}$, $\mathrm{Al}$ and $\mathrm{Bi}$, together with $f^{\text {per }}$, were added for the statistical analysis. The results are listed also in Table 4, and the correlations are illustrated in Fig. $6 b$. These correlations are slightly less scattered in the case of fully ferritic materials than in the whole series of data, in agreement with the difference in $R^{2}$ coefficients.

\section{Discussion}

In the case of binary iron alloys, Leslie ${ }^{14}$ arrived at a particularly interesting correlation between hardness $[\mathrm{HV}(1000 \mathrm{~g})]$ and yield strength (evaluated at $0 \cdot 2 \%$ 
deformation), which is shown with the solid line in Fig. 7. This correlation was found to apply to binary iron based alloys tested at RT, $100^{\circ} \mathrm{C}$ and $200^{\circ} \mathrm{C}$. Data from the literature for fully ferritic nodular cast irons, i.e. either annealed or with $<2 \%$ pearlite in the matrix, have been added in Fig. 7. The bold interrupted line represents data obtained on annealed 65-45-12 grade, ${ }^{8}$ which is seen to lie slightly below the correlation given by Leslie. ${ }^{14}$ Other data for fully ferritic matrix obtained by annealing ${ }^{7}$ overlap this interrupted line. Furthermore, a few results on as cast fully ferritic irons could be found; these are the data from Helmink and Wallace ${ }^{21}$ corresponding to two locations in the keel blocks, either centre or midwall. The authors provided HB hardness values that were converted from Rockwell measurements. The results obtained on fully ferritic as cast materials during the present study have also been reported with crosses. It is seen in Fig. 7 that the average data for the as cast irons appear parallel but slightly shifted with respect to the fit curves for binary Fe alloys and 65-45-12 grade. It could not be settled if these shifts are significant on a metallurgical point of view or are linked to the various types of hardness measurements employed. As it has been established that Rockwell and Brinell hardnesses give most generally the same result when appropriately converted, ${ }^{22}$ a scatter of $\pm 25 \mathrm{HB}$ as observed in the present case may not be significant.

Based on the report of Venugopalan and Alagarsamy, ${ }^{3}$ it was tempting to check if a well defined relation could be established between hardness measured and calculated CMMH values. The composite hardness was estimated here using the above expression for ferrite hardness for all alloys, setting the pearlite term to zero and the one for pearlite previously evaluated ${ }^{18}$ with the ferrite term set similarly to zero. The correlation between CMMH and measured $\mathrm{HB}$ values is shown in Fig. $8 a$, where it is seen that a satisfactory linear relation could be drawn. Then, plotting $Y$ and $U T S$ with respect to $\mathrm{CMMH}$, it is observed that the former gives a more or less satisfactory linear relationship while the latter shows high scattering (Fig. $8 b$ ). Plotting $A$ showed very high scattering as well. Thus, the use of CMMH does not appear as successful as it was in the work of Venugopalan and Alagarsamy, ${ }^{3}$ and this may be due to the large number of interacting alloying elements considered in the present study.

Silicon is the main component determining the RT mechanical properties of cast irons. It is seen that it may appear as both linear and quadratic terms in the correlations established, leading to some more or less marked curvature of the regressions with silicon content. This could be illustrated by plotting the calculated $Y$ values, setting all terms other than silicon content to zero, as in Fig. 9, for both correlations ('ferritic' and 'all alloys'). It is seen that in the composition range investigated, the change in $Y$ values could well be fitted

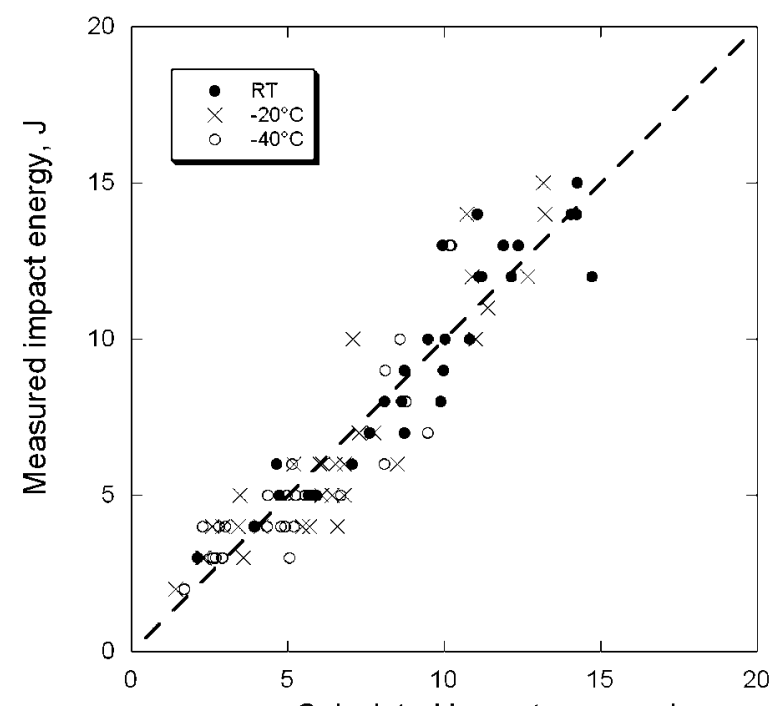

(a) Calculated impact energy, J

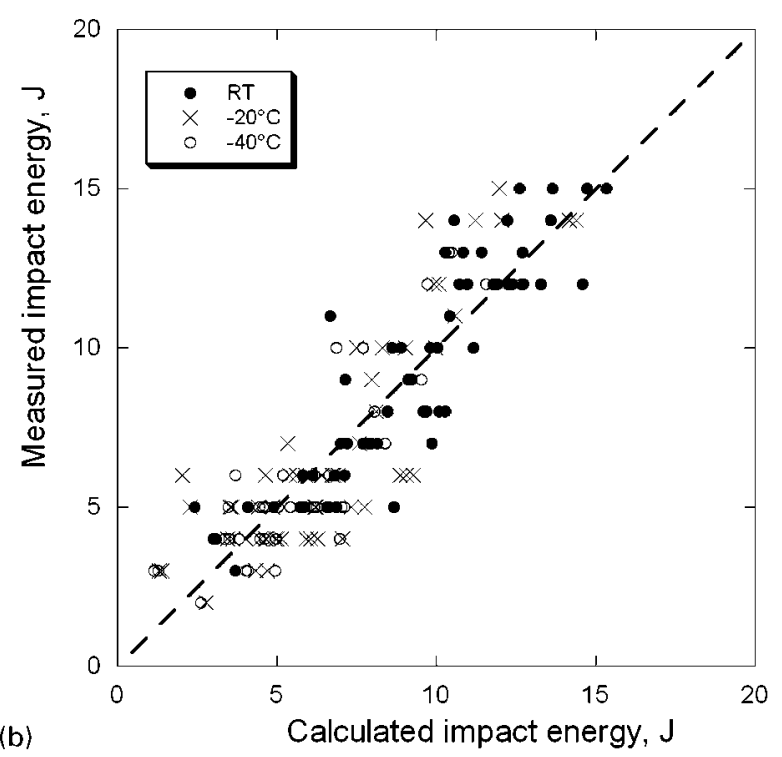

6 Comparison of calculated and measured impact energies at $\mathrm{RT},-20^{\circ} \mathrm{C}$ and $-40^{\circ} \mathrm{C}$ for $a$ fully ferritic alloys and $b$ whole set of alloys: interrupted line in each graph is bisector

with a straight interrupted line that corresponds to an increase of $\sim 100 \mathrm{MPa}$ for each per cent silicon added. Similar estimates of the effect of silicon on UTS, $A$ and $H B$ could be made, though it is not possible to plot graphs as Fig. 9 because of the importance of the terms related to carbon content or $N_{\mathrm{A}}$. All these estimates were found to be in quite good agreement with the data in Table 1.

The second most significant species on RT mechanical properties was found to be $\mathrm{B}$, which appears to strengthen the matrix, i.e. increasing $Y, U T S$ and $H B$ while decreasing $A$ (note that the negative value of the coefficient for $\mathrm{HB}$ 'all alloys' is too low to be significant). Boron being an

Table 4 Coefficients obtained by multivariate analysis on impact energy values at $\mathrm{RT},-20^{\circ} \mathrm{C}$ and $-40^{\circ} \mathrm{C}$

\begin{tabular}{|c|c|c|c|c|c|c|c|c|c|c|c|c|}
\hline & & Constant & $w_{\mathrm{Si}}$ & $w_{\mathrm{B}}$ & $w_{N}$ & $w_{S}$ & $w_{\mathrm{Cu}}$ & $w_{\mathrm{Al}}$ & $w_{\mathrm{Bi}}$ & $N_{\mathrm{A}}$ & $f^{\text {per }}$ & $R^{2}$ \\
\hline \multirow[t]{2}{*}{ RT } & Ferritic & $26 \cdot 24$ & -4.97 & -1043 & $-743 \cdot 0$ & $67 \cdot 61$ & & & & 0.0018 & & 0.89 \\
\hline & All alloys & $20 \cdot 08$ & -3.91 & $-545 \cdot 3$ & $-74 \cdot 4$ & $63 \cdot 82$ & $-31 \cdot 23$ & $32 \cdot 7$ & $-506 \cdot 1$ & 0.0058 & -0.093 & 0.80 \\
\hline \multirow[t]{2}{*}{$-20^{\circ} \mathrm{C}$} & Ferritic & $27 \cdot 70$ & $-5 \cdot 50$ & $-782 \cdot 4$ & $-647 \cdot 1$ & $-358 \cdot 2$ & & & & 0.0059 & & 0.85 \\
\hline & All alloys & $20 \cdot 14$ & $-3 \cdot 70$ & $-240 \cdot 3$ & $-4 \cdot 17$ & $-257 \cdot 2$ & -33.69 & $-211 \cdot 8$ & -411.9 & 0.0089 & -0.032 & 0.74 \\
\hline \multirow[t]{2}{*}{$-40^{\circ} \mathrm{C}$} & Ferritic & $21 \cdot 12$ & $-3 \cdot 73$ & $-535 \cdot 7$ & $-785 \cdot 2$ & $-359 \cdot 2$ & & & & 0.0069 & & 0.78 \\
\hline & All alloys & $16 \cdot 99$ & -2.65 & $-644 \cdot 4$ & $-91 \cdot 72$ & $-342 \cdot 4$ & $-17 \cdot 11$ & $-561 \cdot 8$ & $181 \cdot 2$ & 0.0121 & 0.080 & 0.76 \\
\hline
\end{tabular}




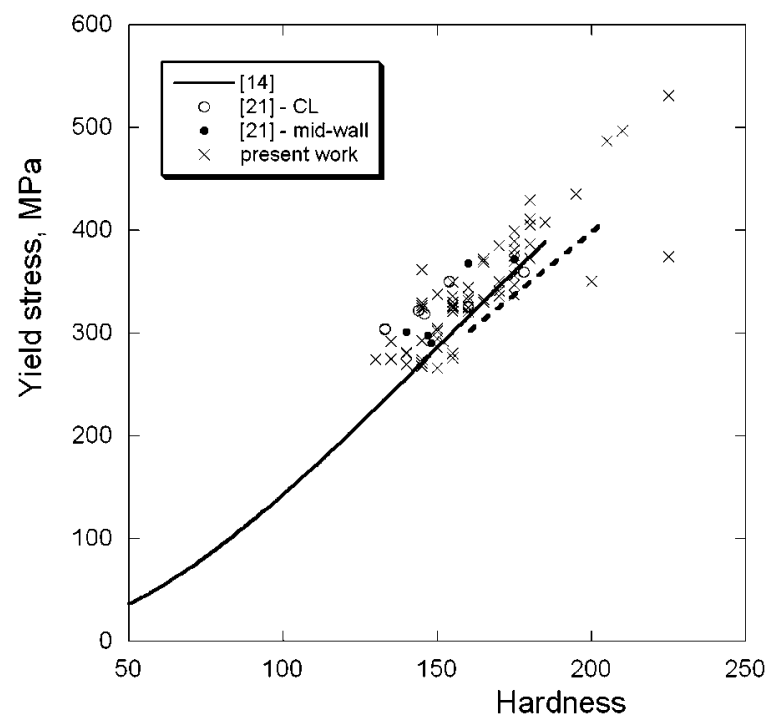

7 Correlation between hardness and yield strength: solid line represents experimental correlation obtained by Leslie $^{14}$ on iron based binary alloys, interrupted line represents correlation reported in ASM handbook for 65-45-12 grade, circles are results from Helmink and Wallace $^{21}$ and crosses are results from present work for fully ferritic samples

interstitial element, its effect could be related to solution strengthening, as is the case of $\mathrm{N}$ in grey and nodular cast irons. ${ }^{23,24}$ Nickel is seen here to affect similarly the tensile properties of all alloys and fully ferritic ones, though with no effect in the present work on $H B$. Even if this species is known as a pearlite refiner, it should thus be accepted that it also affects strongly ferrite properties. Furthermore, the correlation coefficients listed in Table 3 for this element are surprisingly much higher than those appearing in Table 1. As pointed out before, the sign change of the coefficients for Bi from 'ferritic' to 'all alloys' correlations does not allow any conclusions to be drawn. The effect of carbon on $U T S$ and $H B$ relates certainly to graphite and pearlite fraction. It does not seem meaningful to discuss the effect of any of the other elements because of their complex relation with nodule count stressed above. As an example, it could be concluded from Table 3 that $\mathrm{Cu}$ decreases the ferrite hardness when this is definitely contradicted by the literature review (see Table 1).

Figure 10 compares the impact energy results from one of the best of the present alloys with low silicon content to some literature data. Data for grades 400 were reported by Björkegren and Hamberg; ${ }^{25}$ those referenced N1 and N4 are from Fig. 1 after conversion to joules and division of the impact energy by 2.4 to account for the use of a non-standard test sample. ${ }^{12}$ The curve of Labrecque et al. ${ }^{16}$ relates also to castings with low silicon contents $(1 \cdot 8-2 \cdot 2 \mathrm{wt}-\%)$. It seems from this figure that the transition temperature is likely below $-40^{\circ} \mathrm{C}$ for all the alloys containing $\sim 2 \mathrm{wt}-\% \mathrm{Si}$ since the lower shelf does not seem to have been reached at that temperature. The impact energy can reach the target of $12 \mathrm{~J}$ at $-40^{\circ} \mathrm{C}$ provided that the content in $\mathrm{P}$ is $<0.024$ wt- $\%$ and that of $\mathrm{S}$ is $<0.008 \mathrm{wt}-\%$.

As does silicon, Table 4 shows that $\mathrm{B}, \mathrm{N}$ and $\mathrm{S}$ have an effect on the impact energy, which, on the average, appears increasingly negative when the temperature is decreased. Such an effect could be due to the fact that
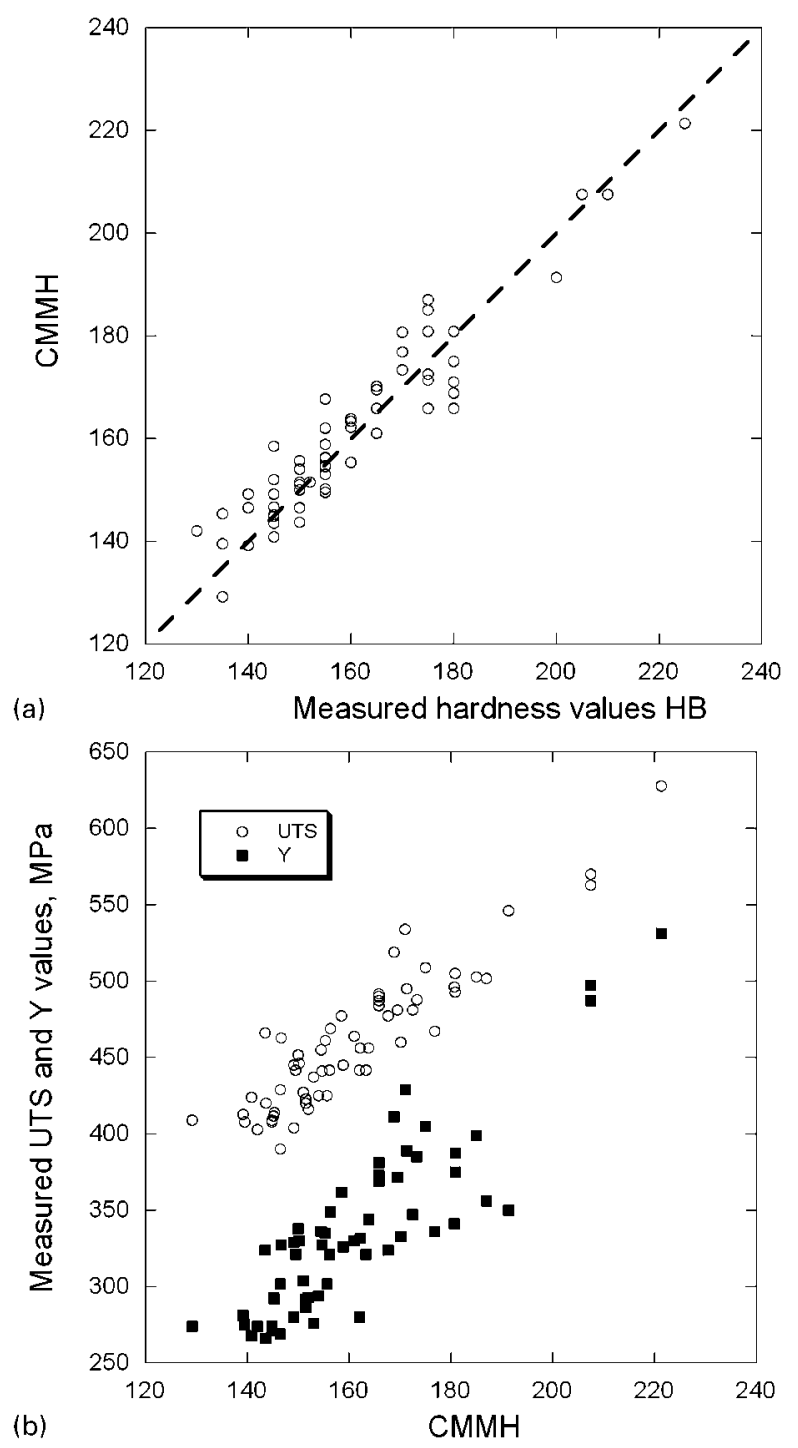

8 Correlation between a CMMH and measured hardness and $b$ CMMH and measured $Y$ and UTS values: interrupted line in $a$ is bisector

these species are known to strongly segregate at ferrite grain boundaries. ${ }^{26}$ That $\mathrm{Cu}, \mathrm{Al}$ and $\mathrm{Bi}$ appear significant is certainly to be associated with complex relationships with nodule count and/or pearlite fraction. It is noteworthy that the nodule count appears to have a positive effect on impact energy, which increases in amplitude with decreasing temperature. This is certainly in agreement with previous works. ${ }^{16,17}$ Finally, Table 4 shows that the fraction of pearlite may have a slight positive effect as the temperature is decreased. The main concern with the analysis of impact energy is that the authors could not find any significant effect of $\mathrm{P}$, as was expected.

\section{Conclusions}

Statistical analysis of all as cast alloys prepared in the present work, with pearlite fraction from 0 to $35 \%$, confirmed the effects of silicon and nickel on RT tensile properties and hardness and that of silicon on impact properties at $\mathrm{RT},-20^{\circ} \mathrm{C}$ and $-40^{\circ} \mathrm{C}$. Investigating either all as cast alloys or only the fully ferritic ones, silicon was found to have similar effects with those reviewed in the introduction. That is, UTS, $Y$ and hardness increase and both $A$ and impact energy 


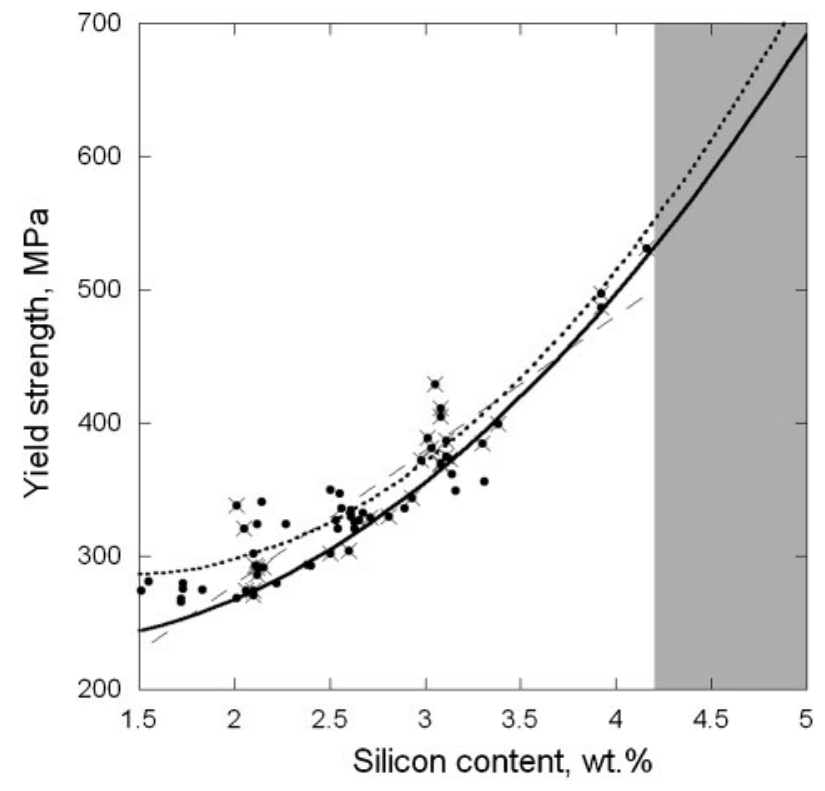

9 Calculated evolution of $Y$ with silicon content according to regression analyses made with all data (dotted line) and with only results from fully ferritic grades (solid line): experimental values have been plotted with dots (all alloys) and crosses (ferritic alloys), composition range investigated corresponds to non-greyed area and interrupted line shows linear interpolation that could be drawn from experimental data

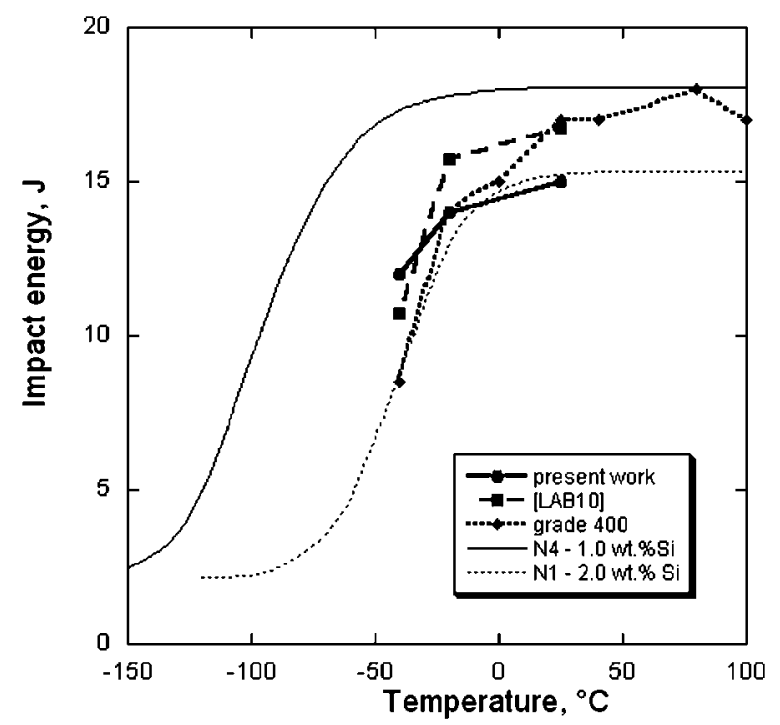

10 Effect of temperature on impact energy of various cast irons (see text for details)

decrease when increasing the silicon content in the alloys. Furthermore, a similar and very strong effect of $\mathrm{Ni}$ on RT tensile properties was observed, while the maximum amount of $\mathrm{Ni}$ added $(0.27 \mathrm{wt}-\%)$ was too small to affect the impact properties.

However, many of the low level elements investigated also showed to affect nodule count and pearlite fraction in a complex way. Thus, it appeared difficult to separate the effect of these latter variables from the intrinsic effects of most of the low level elements on ferrite properties. These inter-relations may explain why even a simple correlation as hardness versus yield strength or ultimate tensile strength showed important scattering. In any case, it was observed that higher nodule counts slightly increase elongation at rupture and impact energies, though this latter effect is more marked at lower temperatures.

Interestingly enough, even though it could only partly be deduced from the statistical analysis, it was found that alloys having impact energy of $>12 \mathrm{~J}$ at $-40^{\circ} \mathrm{C}$ should be fully ferritic, with very low $\mathrm{P}$ and $\mathrm{S}$ contents. While the effect of $\mathrm{P}$ was already known, that of $\mathrm{S}$ does not seem to have been reported before. This negative effect of $\mathrm{P}$ and $\mathrm{S}$ on low temperature impact properties is certainly worthy of further investigation.

\section{Acknowledgement}

The authors would like to thank the financial support obtained from the Centro para el Desarrollo Tecnológico Industrial (CDTI) of the Spanish Government (ref. no. IDI 20071064).

\section{References}

1. T. Watmough, W. F. Shaw and F. C. Bock: AFS Trans., 1971, 79, 225-246.

2. G. M. Goodrich and R. W. Lobenhofer: AFS Trans., 2002, 110 , paper 02-137.

3. D. Venugopalan and A. Alagarsamy: AFS Trans., 1990, 98, 395-400.

4. E. Lundbäck and I. L. Svensson: Proc MCWASP-V, Davos, Switzerland, September 1991, TMS, 479-484.

5. L. E. Björkegren, K. Hamberg and B. Johannesson: AFS Trans., 1996, 104, 139-145.

6. H. Frenz: Doctor's dissertation, 'Eigenschaften von ferritischem und ferritisch-perlitischem Gusseisen mit Kugelgraphit unter besonderer Beachtung des Bruchverhaltens', Technical University of Berlin, Berlin, Germany, 1991.

7. T. Levin, P. C. Rosenthal, C. R. Loper and R. W. Heine: AFS Trans., 1971, 79, 493-514.

8. in 'ASM specialty handbook', 'Cast irons', 54-79; 1996, Materials Park, OH, ASM.

9. D. E. Kippola and G. M. Goodrich: AFS Trans., 2000, 108, 313320 .

10. T. Nobuki, M. Hatate and T. Shiota: IJCMR, 2008, 21, 31-38.

11. P. Donelan: Mater. Sci. Technol., 2000, 16, 261-269.

12. G. N. J. Gilbert: BCIRA J., 1960, 8, 401-421.

13. H. T. Angus: 'Cast iron: physical and engineering properties', 209; 1976, London, Butterworths.

14. W. C. Leslie: Metall. Trans., 1972, 3, 5-26.

15. G. Jolley and G. N. J. Gilbert: Br. Foundryman, 1967, 79-92.

16. C. Labrecque, P. M. Cabanne and E. C. Muratore: Proc. 2010 Word Foundry Cong., Hangzhou, China, October 2010, AFS, 0411-0418.

17. M. Caldera, J. M. Massone, R. E. Boeri and J. A. Sikora: ISIJ Int., 2004, 44, 731-736.

18. J. Serrallach, J. Lacaze, J. Sertucha and R. Suárez: Key Eng. Mater., 2011, 457, 361-366.

19. E. F. Ryntz: AFS Trans., 1976, 82, 551-554.

20. 'Reference microstructure for measurement of pearlite and ferrite content in ductile iron microstructures', AFS current information report, Quality Control Committee 12-E, Ductile Iron Division, 1984.

21. R. C. Helmink and J. I. Wallace: Research project no. 8, Factors affecting optimum properties in heavy section ductile iron, Ductile Iron Society, Mountainside, NJ, USA, 1977.

22. G. E. Dieter: 'Mechanical metallurgy', 3rd edn; 1986, New York, McGraw-Hill, Inc

23. W. M. Nicola and V. L. Richards: AFS Trans., 2000, 108, 127-237.

24. Effects of Room Temperature Aging on Ductile Iron Richards, V L Van Mereau, D C Aken O P Nicola, W MTransactions of the American Foundry Society and the One Hundred Eighth Annual Metalcasting Congress; Rosemont, IL; USA; 12-15 June 2004. pp. 801-812. 2004.

25. L. E. Björkegren and K. Hamberg: Proc. 2003 Keith Millis Symp. on 'Ductile iron', Hilton Head Island, SC, USA, October 2003, Ductile Iron Society, 42-51.

26. W. C. Leslie: 'The physical metallurgy of steels'; 1981, Marietta, $\mathrm{OH}$, Techbooks. 